\title{
Evidences of active and ancient Volcanism on Mars. A review. Second Part
}

\author{
P. Hédervári $(*)$ \\ Received on December 27th, 1973
}

\begin{abstract}
Sumary. - The results of recent research have brought some further evidence of voleanism on the planet Mars. At the same time certain erroneous descriptions and conclusions, which are to be found in the first paper $\left({ }^{3}\right)$, are here corrected.
\end{abstract}

Riassunto. - I risultati di recenti ricerche hanno messo in luce ul. teriori testimonianze circa l'esistenza di vulcanismo sul pianeta Marte. Di conseguenza sono state apportate dall'A. correzioni ad alcune descrizioni e conclusioni presentate nella prima parte della nota $\left({ }^{3}\right)$.

\section{INTRODUCTION}

In our previous paper on Martian volcanism (3), we collected many data in favour the hypothesis according to which volcanic phenomena are not unknown on the planet Mars. Since the elaboration of the respective first paper some other evidence has become known. In addition to the short summing-up of these we should like to correct some erroneous descriptions and in the conclusions which become obsolete in the meantime.

(*) F.R.A.S., Vice-President of International Association of Planetology. 1023 Budapest, II. Árpád fejedelem utja 40.41, IV/3, Hungary. 


\section{1. - Hót spot at a great martian cahomera}

The Mariner 9 infrared rarliation sensor discovered a hot spot at longitude $120^{\circ}$, latitude $10^{\circ} \mathrm{S}$. The area of this spot is some 15 square miles. According to the Mariner 9 map of the Martian surface, the approximate coordinates of the so called South Spot - a mighthy caldera-like formation on the Tharsis Rirge with a diameter of about 120 kilometres - are longitude $119.5^{\circ}$, latitude $9.5^{\circ} \mathrm{S}$. These data refer to the centre of the caldera. One can suppose that the said hot spot may be connected with postvolcanic activity (fumaroles?) within or very near this callera.

\section{2. - MEANDERING VAILLEYS}

After the discovery of the meandering valleys on the Moon many authors at first suggested that they are the remnants of ancient rivers. Later on, however, this concept was abandoned, and now the generally accepted view is that the lunar meandering valleys are due to the work of lava. The situation in the case of the Martion meandering valleys is just the opposite. At first it was suggesterl that these features were due to lava-flows, but this is already obsoleted and at present the general opinion is that these Martian valleys are the remnants of water-courses.

3. - Eartier observations regardotsg Martian phexomexa Which ARE ATTRIBLTED TO VOLCANIC AC'TIVITY

Mr. V. A. Firsoff of Glastonbury (Somerset, England) had the kindness to inform the present author about some further data regarding earlier observations of Martian phenomena which can be interpreted as volcanic manifestations (private communication). Thus:

"... Indeed on rare occasions grey circular clouds have been seen to arise suddenly, appearing to spread out mushroom-wise from a point on the surface. Antoniadi observed such clouds in 1909 and 1911 in the so-called Deucalionis Regio and identified them as volcanic ash, mainly on the strength of their dimness and grey colouring". The height of these clouds was estimated (later) as 60-120 miles by Saheki and Murayama. "Four further clouds of this type were report- 
erl by Japanese observers in 1950 and 1952. Deucalionis Regio is particularly favoured by these appearances, but on 15, January, 1950 Tsuneo Saheki and two other Japanese astronomer's observed a similar grey clour, about 460 miles in cliameter, over Erydania and Electris. These clouls have also been seen to fluctuate in colour between grey, bluish white and dull yellow within the space of a few clays".

\section{4. - NIX OLYmPich}

The first photos of the gigantic voleano, Nix Olympica of Mars, were somewhat insteading and thus led to misunderstandings. As one can see on the enclosed photo (Fig. 1), in reality Nix Olympica

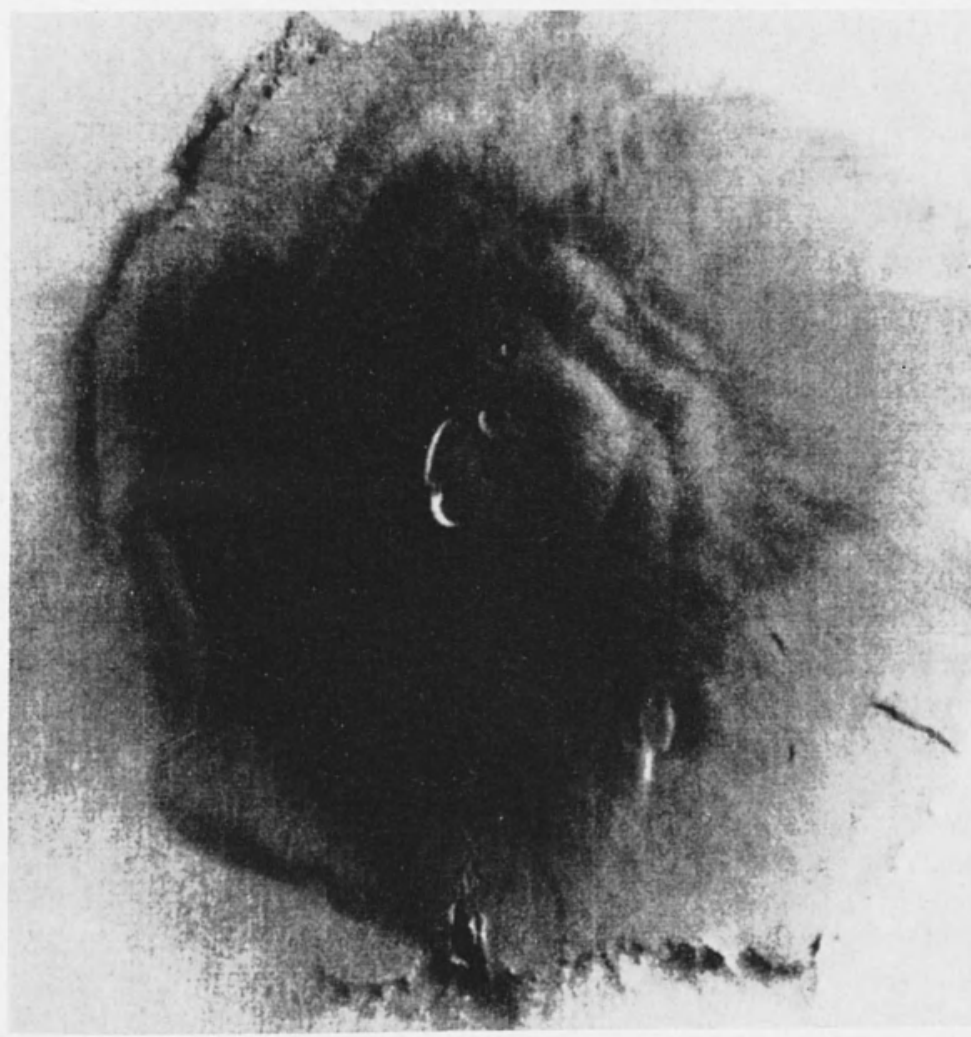

Fig. 1 - A new photo of Nix Olympica roleano (Mariner 9, after Murray, 1973). 
is a volcanic cone of the shield-type with a diameter of about 520 kilometres and with a height of about 25 kilometres (!) $\left({ }^{3,7}\right)$. The caldera which is to be found on the top of the volcanic structure has a diameter of some 64 kilometres and thus within this caldera we could put about ten Vesuvius. The mass of this volcano is estimated as $2.4 \cdot 10^{21} \mathrm{gm}$ while that of the Mars as a whole is equal to $6.4 \cdot 10^{26}$ gm $\left.{ }^{8}\right)$. In spite of its extraordinary height, Nix Olympica has a rather flat form (Fig. 2) which is characteristical to shield-volcanoes.
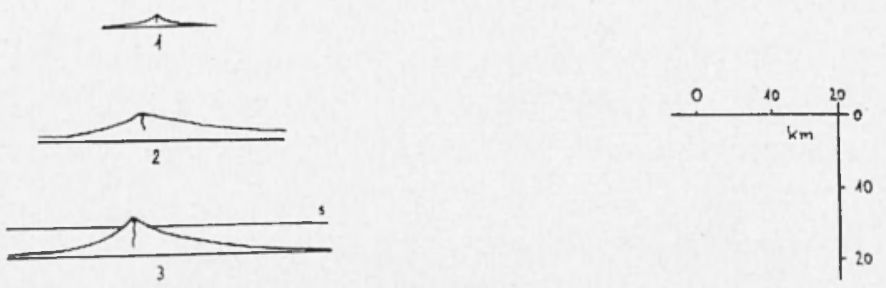

c

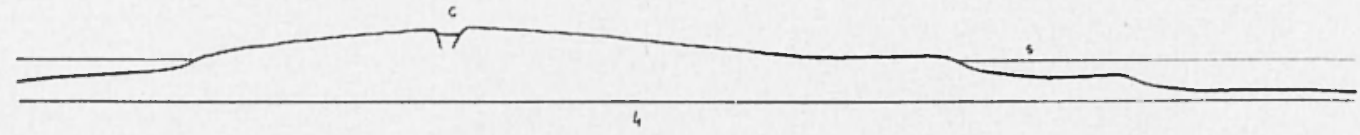

c

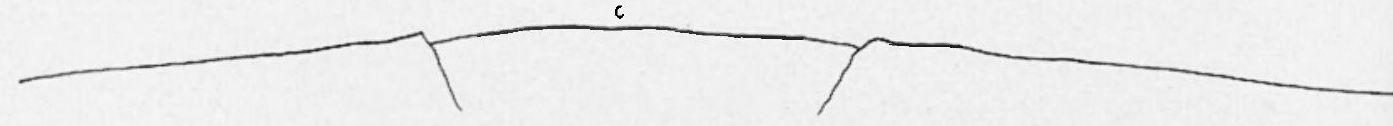

Firr. 2 - Comparison among some terrestrial voleanoes and Nix Olympica. 1: Vesuvius; 2: Etna; 3: Stromboli: 4: Mauna Loa (1-4: after Menard W. H.: Marine Geology of the Pacific, 1964, publ. by McGraw-Hill, Inc.); 5: Nix Olympica. s: sea-level; c: top-caldera.

Some statements of the previous paper must now be corrected. $\Lambda$ ccordingly, the eaption to Fig. 7 , should read: " $\Lambda$ detailed photomosaic of the Nix-Olympica cone together with its top-caldera". Fig. 8: " $\Lambda$ part of Nix Olympica's slope". Page 502, lines 10-15 (from above) is to be corrected as follows: ". . the Mariner 9' cameras have not only found an ancient volcano but also revealed that on the top of the volcanic structure there is a great caldera with a diameter of 
about 64 kilometres. We can see on the enlarged photo of the slope of the Nix Olympica volcano that there is an apparently fresh lavaflow without small impact craters".

The long chasm, mentioned many times in the first paper is the Coprates canyon.

\section{5. - Hellas}

According to the recent research Hellas can be regarded as a true, rather deep basin, perhaps of impact origin, rather than a gigantic caldera of collapse origin.

\section{6. - Basins aNd Martian "CONTINents"}

Sagan and Pollack ( $\left.{ }^{9}\right)$ - partly on the basis of cloud-observations and partly of radar-measurements - have suggested that the dark areas of Mars may generally be elevations, while the light ones can be regarded as basins. Recent measurements and investigations of the distribution of carbon-dioxide in the Martian atmosphere ${ }^{(10)}$ have revealed, however, that there is no general agreement between the colour and height of the different surfacial areas of Mars. According to Wells and other authors, dark areas may be lowlands or highlands, that is depressed or elevated regions alike and the same is true of the light regions (Fig. 3). Therefore the suggestion that the supposedly volcanic events on Mars are distributed first of all along the margins of "continental" areas, in all probability is not correct in such a strict formulation.

As regards the true nature of the dark areas, Binder and Cruikshank (1.2) have suggested that there are no structural but only surfacial differences between the light and dark regions, as the latter may be covered with dark, dusty materials. The present author favours the opinion of D. McLaughlin of the University of Michigan, who is of the view that the major dark markings on Mars, are produced by the deposition of volcanic dust, due to the recent activity of the Martian volcanoes.

This idea seems to be very probable, especially if we take into consideration that the greatest volcanoes of Mars are to be found near 


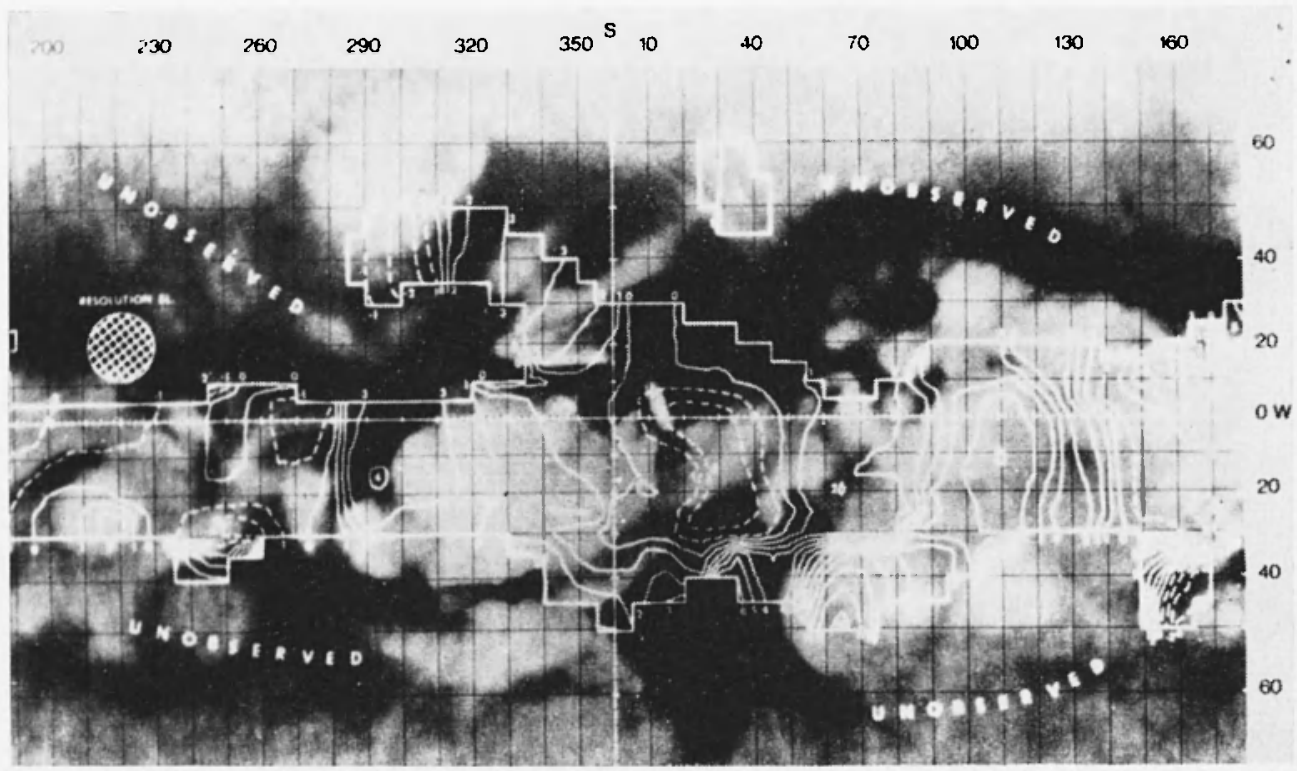

Fir. 3 - Rolief-map of IIars (after Wells, 1972). The height-contours were produed from the combined data soures listed in the respective paper. solid lines represent zero and positive relief, the dashed ones correspond to negative topography. Numbers mean libmetres.

the equator and - as Miyamoto $\left(^{\circ}\right)$ has demonstrated - that strong air-movements crossing the equator are possible on Mars. We can refer to some terestrial examples, such as the distribution of volcanic dust over many parts of the larth after the Kakatoa outburst in 1883 or after the Agung eruption of 196:3. In the latter case volcanic materials, originated from Jgung (Indonesia), had been found in North America, thile and even on the land of Antaretica.

\section{7. - THE GREY STREAK}

On Fig. 1 of the previous paper the grey streak, observed by C. F. Capen of the Flagstafi Observatory, was shown on the map as a straight line. Capen has kindly to call the anthor's attention (private communication) that this grey streak has a curved form instead of a straight line, as originally portrayed in a chart published by H. Heu- 


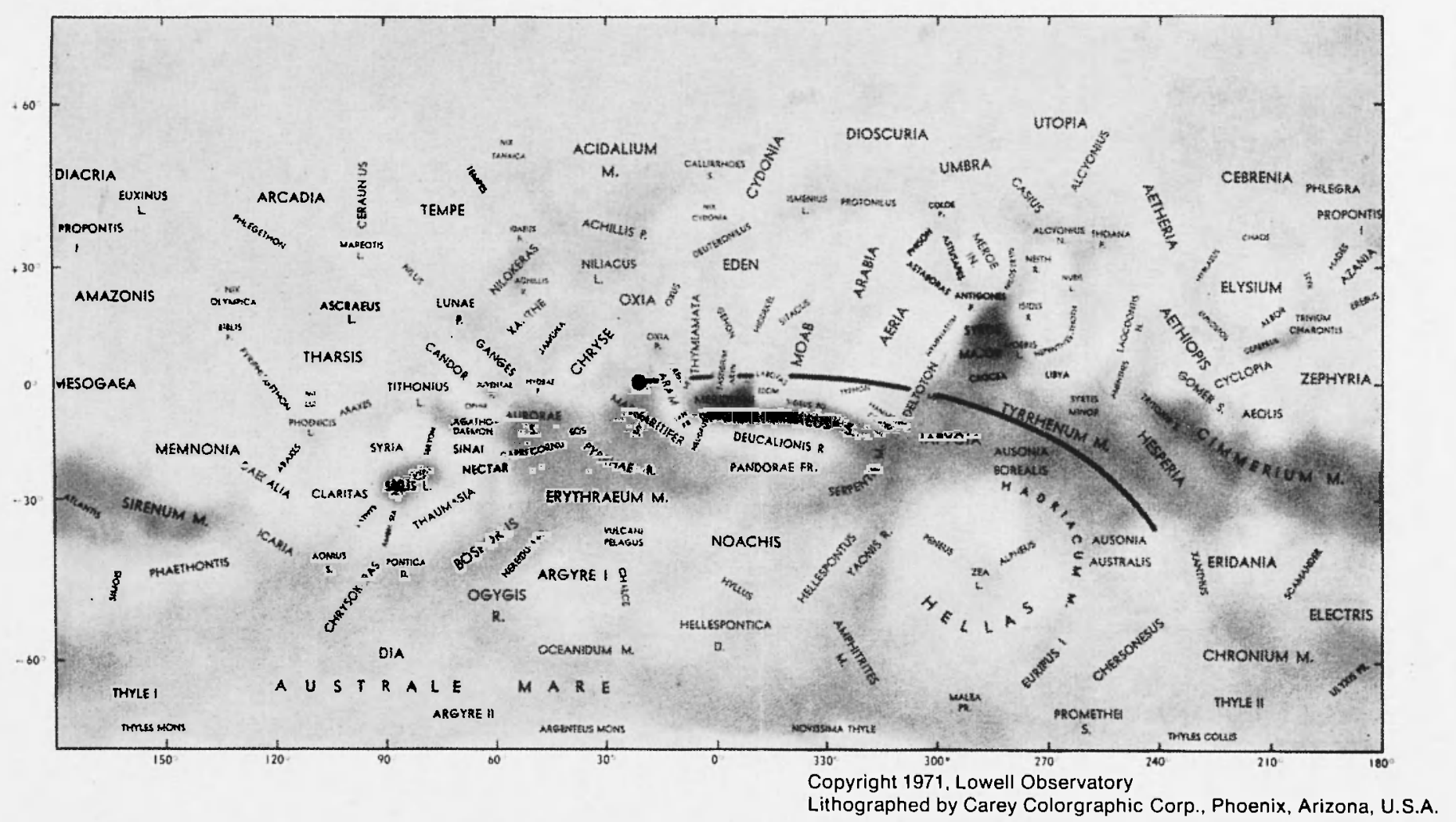

Fig. 4 - The location of the grey streak, indicated on a map, published hy Lowell Observatory (after (apen's information). 
seler (4). Our present Fig. 4 shows the position and form of the said grey streak in accordance with the information, the author had received from Capen, who has suggested that the streak is probably due not to a very long linear (fissure) eruption but rather to a central one and the curvilinear form of the eruption-cloud was the consequence of the wind prevailing on the Mars during and after this central eruption.

\section{ACKNOWLEDGEMENT}

The author is very indebted to Dr. C. F. Capen of Flagstaff and Mr. V. A. Firsoff of Glastonbury for their valuable remarks, information and data with which they have kindly provided him.

\section{REFERENCES}

(1) Binder A. B., Cruikshank D. P., 1964. - Comm. of the Lunar and Planet. Lab., 2, 36-39.

(2) Binder A. B., Cruiksinnk D. P., 1966. - Comm. of the Lunar and Planet. Lab., 4, 64-69.

(3) IIÉdervari P., 1972. - "Annali di Geofisica", XXV, 4, 1972.

(4) Heuseler H., 1969. - "Die Sterne", 45, 7-8.

(5) MCCauiey J. F. et al., 1972. - Preliminary Mariner Report on the Geology of Mars. "NASA", Contract NAS7-100.

(6) Mчнмото S., 1963. - Contr. from the "Inst. of Astrophys." and "Kwasan Obs.", Univ. of Kyoto, 125.

(7) Murray B. C., 1973. - "Scientific Am.", 228, 1.

(8) Murray B. C., Malin M. C., 1972. - Contr. No. 2199 of the "Div. of Geol. and Planet. Sci., "CALTECH", (preprint).

(9) SaGan (., Pollack J. B., 1968. - "Journ. Geophys. Res.", 73, 4.

(10) Wells R. A., 1972. - "The Geophys. Journ.", 27, 101-133. 